\title{
KORELASI KONSEP SUNAT DALAM PERJANJIAN LAMA DENGAN BUDAYA SUNAT DI MASYARAKAT NIAS
}

\author{
Steven Anugerah Jaya Ndruru, Firman Panjaitan
}

Sekolah Tinggi Teologi Tawangmangu

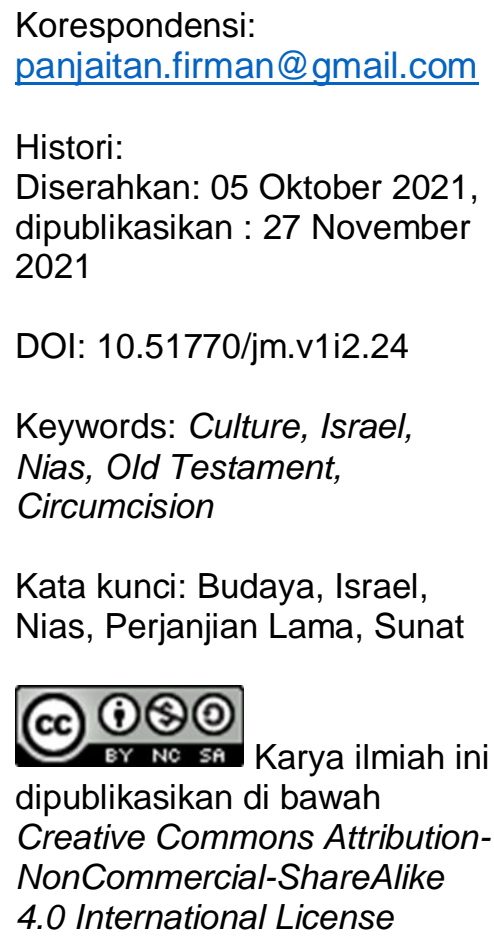

Abstract. In the Old Testament, circumcision was seen as a major part of establishing oneself as part of God's people. In the adoption of Israel as God's people at Sinai, every Israelite must be circumcised. It is based on God's command to Abraham, as a sign of the covenant. But actually the culture of circumcision is not a typical Israeli culture, but is a culture that is common in the Middle East, the only thing that distinguishes the culture of Israeli circumcision from the Middle East is in God's decree in the covenant that raised Israel (a descendant of Abraham) as God's people. So there is a spiritual meaning in the cultural content of circumcision in the Old Testament for the Israelites. It turns out that the spiritual understanding of circumcision is not only owned by Israel, because this is also owned by the Nias Tribe. By using qualitative research methods, which are complemented by a literature study approach, this research results in an understanding that the culture of circumcision for the Nias tribe is a culture that signifies them as God's people. So that circumcision is an absolute for every Nias community.

Abstrak. Dalam Perjanjian Lama, sunat dipandang sebagai bagian utama dalam menetapkan diri sebagai bagian dari umat Allah. Dalam pengangkatan Israel sebagai umat Allah di Sinai, maka setiap orang Israel harus disunat. Hal ini didasarkan pada perintah Allah kepada Abraham, sebagai tanda perjanjian. Namun sebenarnya budaya sunat bukanlah budaya khas Israel, melainkan merupakan budaya yng sudah umum di Timur Tengah, hanya yang membedakan budaya sunat Israel dengan Timur Tengah adalah pada ketetapan Allah dalam perjanjian yang mengangkat Israel (keturunan Abraham) sebagai umat Allah. Jadi ada makna rohani dalam kandungan budaya sunat dalam Perjanjian Lama bagi bangsa Israel. Pemahaman rohani dalam sunat ternyata bukan sekadar dimiliki oleh Israel, karena hal ini pun dimiliki oleh Suku Nias. Dengan menggunakan metode penelitian kualitatif, yang dilengkapi dengan pendekatan studi literatur, maka penelitian ini menghasilkan pemahaman bahwa budaya sunat bagi suku Nias merupakan budaya yang menandakan mereka sebagai umat Allah. Sehingga sunat merupakan kemutlakan bagi setiap masyarakat Nias. 


\section{PENDAHULUAN}

Pada zaman Perjanjian Lama sunat digunakan sebagai bentuk perjanjian Allah kepada umat-Nya (Derouchie 2004) yang telah diselamatkan. Bahkan jika tidak melakukan sunat, hal itu akan mendatangkan hukuman (Kej. 17:14; Kel. 4:24, 26), mereka juga tidak diperkenan Allah untuk melakukan kawin campur dengan orang yang tidak bersunat (Kej. 34:14; Hak 14:3), dan tidak boleh bergaul dengan orang yang tidak bersunat (Kis. 10:28; 11:3; Gal. 2:112) (Suroso, n.d.). Naskah Perjanjian lama mencatat bahwa praktik sunat tidak hanya dilakukan oleh bangsa Isarel, melainkan beberapa bangsa seperti Afrika, Australia, Amerika, dan Astronesia, terlebih lagi bangsa-bangsa di daerah Timur Tengah, selain bangsa Asyur, Filistin, dan Babel (Hak. 14:3; 15:18; 1 Sam. 14:6, 36, 2Sam. 1:20, dll.) (Wismoyoadi 1978).

Kejadian 17 telah menjadi catatan sejarah bagi bangsa Israel mengenai praktik sunat di dalam tradisi mereka. Penulis Kejadian sendiri meringkas sekali mengenai hal ini, sebagai ikhtiar penyunatan wajib. Sehingga praktik sunat ini dilakukan turun temurun di dalam budaya Yahudi (lih. Kel. 4:24-26 dan Yos. 5:2-8); akan tetapi setelah pembuangan Israel ke Babel, membuat praktik sunat menjadi tanda yang utama bagi jemaat, yaitu sebagai syarat mutlak jemaat Yahudi (Walter Lempp 1994). Para imam Israel pada masa itu (sesudah atau sebelum pembuangan) hendak mengesahkan praktik sunat itu sebagai perintah Allah yang telah 
diberikan-Nya kepada Abraham sebagai raja, datuk bangsa Yahudi, bahkan ketika perjanjian tersebut sampai kepada Abraham pertama kalinya, ia pun juga menyunatkan seluruh orang yang ada di rumahnya (“Genesis $17: 10-14$, , n.d.). Jika Abraham sebagai nenek moyang bangsa Yahudi, maka mereka harus meneruskan tradisi tersebut (Marpay and Tarigan 2011), sehingga Kejadian 17 disebut dengan cerita-sebab (aitiologi); meskipun bukan berasal dari masa kuno, melainkan adalah hasil pertimbangan teologis dari para imam Israel. Di sini tampak bahwa penulis kitab Kejadian sedang membentangkan suatu bentuk teologi Perjanjian Lama kepada bangsa Israel (Walter Lempp 1994).

Makna teologis di dalam praktik sunat pada bangsa Israel tidak hanya sekadar menjadi sebuah identitas bagi orang-orang Yahudi, akan tetapi ada makna tersembunyi dari praktik sunat lebih dari suatu tanda fisik, ada juga ada kandungan makna rohani (Panjaitan 2019). Secara umum berbagai negara dan agama tertentu telah menjadikan praktik sunat ini sebagai salah satu budaya mereka, sehingga perkembangan praktik tersebut telah tersebar diberbagai bangsa. Banyak dokter berbicara mengenai praktik ini, yaitu bahwa dapat memberikan dampak yang baik bagi kesehatan kelamin pria dan menghindarkan pria dari berbagai penyakit kelamin ("Jangan Takut, Sunat Beri Banyak Manfaat Bagi Kesehatan" n.d.). 
Salah satu suku yang mempraktikan sunat sampai hari ini adalah suku Nias, suku yang memelihara kebudayaannya sampai hari ini. Dalam hukum adat Nias, yang secara umum disebut Fondrakö, diatur segala segi kehidupan mulai dari kelahiran sampai kematian. Salah satu yang diatur dalam hukum adat itu adalah sunat, yang dipandang sebagai bagian dari budaya masyarakat suku Nias yang masih dilestarikan sampai sekarang. Dalam kearifan lokal terdapat beberapa karakter yang mendefinisikan kebudayaan suku bangsa Nias, di antaranya: etika, kesehatan, sosial kemasyarakatan, kelestarian lingkungan, kondisi alam, dan lain-lain (Dewantara Bangun 2018).

Tradisi sunat ini terus berkembang sampai dengan hari ini, terus berkembang di kalangan masyarakat Nias, bukan saja untuk fungsi kesehatan tetapi juga sebagai bukti ketundukan pada kebudayaan masyarakat Nias. Pada artikel ini penulis akan mencoba melihat makna sunat di dalam Perjanjian Lama dan korelasinya dengan budaya sunat di Nias. Ada dua sunat yang disebutkan dalam Perjanjian Lama, yaitu sunat kulup yang dicatat dalam kitab Kejadian dan sunat rohani yang kitab Yeremia dan Yehezkiel. Makna sunat dalam budaya Nias sesuai dengan dua jenis sunat dalam perjanjian lama. Inilah yang penulis tetapkan sebagai rumusan masalah pada artikel ini.

Dengan demikian tujuan dari penulisan ini adalah untuk menjelaskan mengenai konsep sunat dalam Perjanjian Lama beserta maknanya dan 
hubungannya dengan budaya sunat di kalangan masyarakat Nias. Hingga menerangkan berbagai sejarah mengenai praktik sunat itu sendiri hingga praktik tersebut diadopsi oleh bangsa Israel sebagai tanda perjanjian dan makna sunat dalam budaya Nias.

\section{Metode Penelitian}

Penelitian ini akan menggunakan metode kualitatif, khususnya melalui pendekatan studi literatur dan studi pustaka. Penulis berusaha menjawab rumusan masalah dengan berbagai literatur yang berkorelasi dengan penelitian tersebut. Mengutip berbagai sumber-sumber literatur cetak maupun online yang dapat dipertanggungjawabkan dan juga dari beberapa sumber wawancara kepada tokoh tua-tua yang ada di pulau Nias.

\section{HASIL PENELITIAN}

Hasil penelitian dari artikel ini membuktikan bahwa budaya sunat dalam Perjanjian Lama bukanlah merupakan tradisi khas dari bangsa Israel, melainkan sudah menjadi ciri khas budaya Timur Tengah. Abraham memberikan makna baru dalam pemahaman sunat, yaitu pengangkatan bangsa Israel sebagai umat Allah. Inilah yang membedakan antara sunat di Israel dengan bangsa-bangsa Timur Tengah. Hal ini juga yang dipahami oleh masyarakat Nias, di mana sunat dipahami sebagai bentuk dari ikatan perjanjian antara masyarakat Nias 
dengan Tuhannya. Dengan demikian, sunat di masyarakat Nias menjadi sebuah keniscayaan bahkan keharusan dalam hidup mereka sebagai umat Allah.

\section{PEMBAHASAN}

\section{Riwayat Tradisi Sunat}

Banyak orang mengira bahwa praktik sunat adalah suatu praktik yang lahir antara Abraham dan Allah sebagai bentuk perjanjian di antara mereka. Akan tetapi, jejak sejarah melalui penelitian arkeologi menemukan bahwa praktik tersebut telah lama ada di beberapa bangsa kuno, antara lain adalah Mesir Kuno. Teori terbaru juga menunjukkan bahwa kebudayaan Arab Selatan dan sebagian Afrika juga melakukannya. Menurut Ancient Origins sunat seringkali digunakan sebagai ritual keagamaan, ritual kedewasaan, dan sebagai hukuman pada masa perang (Risa Herdahita Putri 2019).

Doyle mencatat bahwa sunat telah dipraktikkan di Mesir, kepulauan Laut Selatan, Australia (suku Aborigin), suku Inca, Aztec, dan Maya (D. Doyle 2005). Di bagian lain Dunsmuir mencatat bahwa sunat sebagai tanda kekotoran dan perbudakan. Di Mesir Kuno, seringkali prajurit yang mereka tangkap dimutilasi sebelum mereka jadikan budak (Dunsmuir and Gordon 2002). 


\section{Sunat di Mesir Kuno}

Berbagai bukti arkeolog telah menemukan fakta bahwa referensi terlama praktik sunat dilakukan oleh orang-orang Mesir Kuno. Hal tersebut terlacak melalui relief di tanah pemakaman kuno Saqqara yang mengilustrasikan serangkaian adegan medis, termasuk sunat pisau sehingga negeri para Firaun ini menjadi pencetus pertama praktik sunat (Caleb Strom 2018). Meskipun Doyle (D. Doyle 2005) sendiri memperkirakan bahwa bangsa Mesir Kuno juga mengadopsi praktik tersebut dari orang-orang yang jauh di Selatan, yang sekarang menjadi wilayah Sudan dan Ethiopia, akan tetapi hal itu barulah sebuah spekulasi tanpa bukti arkeologi. Karna orang-orang Selatan itu secara genetik terkait erat dengan bangsa Sumerian dan Semit. Merekaa menurut para antropolog berasal dari Semenanjung Arab dan telah melakukan kontak rutin, seperti berdagang maupun dengan orang Mesir (Risa Herdahita Putri 2019).

Di Mesir Kuno, praktik ini dilakukan bagi pria yang akan diinisiasi menjadi seorang dewasa yang tergolong sebagai kaum bangsawan. Sunat juga digunakan untuk membatasi kelas elite khusus. Tidak seperti bangsa Israel yang menjadikan praktik ini sebagai tanda perjanjian kepada Allah.

\section{Sunat di Afrika}


Mesir bukanlah satu-satunya suatu budaya Afrika yang mempraktikan sunat. Praktik sunat telah menjadi hal yang umum bagi masyarakat Afrika Timur. Seorang remaja pria dari etnis Xhosa dan Zulu secara tradisional memiliki ritual sunat yang rumit, di mana mereka mesti dicat dengan kapur sebelum disunat. Setelah itu mereka akan terlebih dahulu diisolasi dari komunitasnya hingga beberapa Minggu. Pria tersebut juga dilarang untuk bersinggungan dengan para wanita. Setelah sunat berlalu, pria yang disunat akan meletakkan kulit khitan itu didalam hutan, sebagai simbol bahwa ia telah meninggalkan masa kecil mereka dan menuju pada pendewasaan diri. Ketika semua sudah selesai barulah ia mencucu diri di sungai (Risa Herdahita Putri 2019).

\section{Sunat di Kawasan Oceania}

Menurut sejarah sunat tidak hanya dilakukan di daerah Afrika maupun Timur Tengah saja, melainkan wilayah Oceania dan Australia oleh suku Aborigin. Mereka menggunakan kerang laut sebagai alat untuk memotong kulit kulupnya. Orang yang disunat ditahan tubuhnya untuk menghadap ke atas. Dia dibaringkan ditubuh seorang pria yang berlutut. Lengan dan kakinya dipegangi oleh pria yang lain.

Agar menghentikan pendarahan tersebut, menurut Doyle (2005), mereka harus berdiri atau jongkok di atas asap dari api yang ditutupi dengan daun kayu putih selama beberapa jam. la menjelaskan juga bahwa darah yang menetes ke dalam api tersebut adalah sebuah simbol 
simpati kepada perempuan yang menstruasi (Risa Herdahita Putri 2019). Di Oceania dan Australia, makna sunat itu sendiri adalah sebagai tanda seorang pria telah beranjak menjadi dewasa, sekaligus ujian keberanian.

Meskipun banyak berbagai wilayah yang telah melakukan praktik sunat tersebut, akan tetapi menjadi suatu ritual yang sangat berpengaruh signifikan bagi bangsa Israel, karena bagi bangsa Israel praktik sunat telah menjadi sebuah tanda bagi etnis Yahudi (Muhammad Sholeh 2021). Walaupun Abraham mengadopsi praktik tersebut dari bangsa yang ada disekitarnya, namun makna di dalam praktik yang dilakukan oleh keturunan Abraham mengandung makna teologis yang sangat penting bagi keberadaan bangsa Israel. Jika bangsa lain memandang praktik ini hanya sebagai kesehatan medis, yang dilakukan pada usia remaja untuk kesuburan alat kelamin pria. Allah Abraham memerintahkan praktik sunat ini dilakukan pada bayi laki-laki yang berusia delapan hari. Di mana Allah mau menunjukkan bahwa praktik ini tidak hanya berkepentingan bagi kesehatan kesuburan kelamin pria, namun juga untuk menyampaikan makna rohani bagi bangsa Israel.

\section{Konsep Sunat di dalam Perjanjian Lama}

Sunat adalah salah satu bukti perjanjian Allah kepada Abraham. Kata 'perjanjian' di dalam bahasa Ibrani ditulis sebagai berit. Kata ini di dalam Perjanjian Lama dituliskan singga 400 kali (Samuel Umbu Pingge, n.d.). Di dalam bahasa Inggris kata ini dapat dibedakan menjadi dua, 
yaitu convenant dan testament (Crampton 2000). Meskipun kedua istilah tersebut berbeda, namun lebih banyak kesamaannya, sebab:

"Perjanjian anugerah itu acap kali dikemukakan dalam Alkitab dengan nama wasiat. Nama itu mengacu pada kematian Yesus Kristus, yang adalah pembuat wasiat itu, dan pada warisan kekal serta segala hal yang termasuk padanya, yang diwariskan di dalam wasiat itu" (Van den End 2000).

Melalui perbedaan istilah di atas dapat dipahami bahwa covenat mengacu pada peletakan suatu fakta janji keselamatan, sedangkan 'wasiat' mengacu pada fakta pemenuhan janji keselamatan tersebut (Samuel Umbu Pingge, n.d.). Kata Perjanjian (Ibrani: berit) memiliki arti ikatan antara dua pihak yang saling memberikan janji dan menuntut setia (Risa Herdahita Putri 2019). Dalam konteks kitab Kejadian 17 perjanjian ini dilakukan antara Allah dan manusia.

Di dalam Perjanjian Lama hal ini pasti berkaitan erat dengan upacara penumpahan darah (Risa Herdahita Putri 2019). Demikian juga perihal praktik sunat yang menjadi bentuk perjanjian keturunan Abraham kepada Allah. Normalnya praktik sunat ini pasti akan menimbulkan pendarahan kecil saat kulit kulup pada alat kelamin pria tersebut di potong, demikianlah dokter bedah anak Yessi Eldiyani ("Setelah Anak Disunat, Cek Berbagai Kondisi Yang Menyertainya - Health Liputan6.Com" n.d.) dan Dr. Novalia Arisandy ("Darah Masih Keluar Dari Bekas Luka Sunat - Tanya Alodokter" n.d.) menjelaskannya. Setiap kali orang Yahudi melaksankan praktik sunat, disitu ada kandungan teologi yang berbicara mengenai janji Allah 
kepada keturunan Abraham, supaya mereka hidup selayaknya umat perjanjian. Kebimbangan Abraham ketika sedang menantikan janji Allah mengenai anak yang akan dikandung Sara, membuat Abraham terhasut untuk mengangkat hambanya Hagar untuk meneruskan keturunannya. Akan tetapi, Allah tetap menepati janjinya kepada Abraham bahwa Saralah yang akan mengandung anak perjanjian tersebut. Ketika Abraham berumur 99 tahun mengandunglah Sara, setelah itu perjanjian diperbarui dan ditetapkanlah sunat sebagai tanda perjanjian yang nyata (Kej.17:1-27; bnd 12:1-3; 13:14-18; 15:18-21) (Schultz 2006). Demikianlah hadirnya suatu konsep perjanjian yang baru mengenai sunat kulup bagi orang Yahudi di dalam naskah kuno Perjanjian Lama.

Naskah kuno Perjanjian Lama yang menjadi acuan penulis dalam merangkai materi ini tidak hanya mencatat perihal sunat di dalam kitab Kejadian saja, melainkan ada dua kitab lain yang menyampaikan perihal sunat yaitu kitab Yeremia dan kitab Yehezkiel yang menyatakan mengenai sunat telinga dan sunat hati. Hal ini menjadi suatu pergumulan bagi bangsa Israel pada akhir zaman pembuangan (Suroso, n.d.). Dekade terakhir pemerintahan Manasye menjadi suatu masa yang penuh dengan kemrosotan dan kehancuran moral. Pemerintahan yang berjalan hampir setengah abad ini diwarnai dengan maraknya kembali praktik penyembahan dewa-dewa Kanaan dan Asyur, praktik kuasa gelap, pengorbanan manusia dan sistem peradilan yang bobrok (Derek Kidner 
1996). Hal inilah yang menjadi alasan bagi Yeremia menyinggung mereka dengan mengingatkan mengenai praktik sunat yang mereka lakukan yang semestinya membuat mereka tetap hidup selayaknya umat Allah.

\section{Makna Sunat Kulup}

Sunat yang sebagai bentuk perjanjian Allah dengan keturunan Abraham secara fisik membuktikan bahwa keturunan Abraham adalah orang-orang pilihan. Orang-orang yang harus hidup berbeda dengan bangsa lain yang tidak bersunat. Di dalam perkembangannya makna sunat kulup mendapatkan bentuk rohani yang tegas ketika mereka berada di pembuangan Babel, pada abad ke 5 dan 6 (Suroso, n.d.). Kondisi bangsa Israel pada waktu itulah yang mempelopori munculnya teks Yeremia 4:4 untuk menyinggung mereka yang telah bersunat tetapi hidup dengan keinginannya sendiri. Di sini dapat diketahui bahwa sunat tidak hanya berupa praktik fisik, melainkan juga memiliki makna rohani.

Michael Fox, seperti yang dikutip oleh Derouchie, menyatakan bahwa praktik sunat kulup adalah suatu bentuk simbolik yang mengandung makna rohani, diantaraya adalah darah yang keluar ketika seseorang melakukan praktik sunat yang menjadi analogi dari darah domba paskah untuk mengidentifikasi rumah-rumah orang Israel ketika mereka berada di Mesir (Kel. 12:13), dan tongkat Harun yang mekar adalah tanda yang mengingatkan bahwa mereka adalah kaum pilihan Allah (Derouchie 2004). Sedangkan, Pingge berpendapat bahwa ketika 
dilakukan pembersihan saat praktik sunat melambangkan pembersihan dosa umat Israel oleh Allah sendiri. Jika, pada masa itu bangsa Israel memandang bahwa sunat hanya bertujuan untuk pembersihan lahiriah, maka Allah ingin menunjukkan sesuatu yang lebih bermakna dari hal itu. Bangsa di sekitar Abraham melakukan praktik sunat pada usia remaja untuk pembersihan kesuburan, maka Allah mengubah tanda itu dengan menyunatkan bayi yang telah berusia delapan hari, untuk menunjukkan bahwa Allah membersihkan mereka secara menyeluruh didalam batiniah mereka, Allah mengasingkan atau menguduskan mereka agar menerima pembenaran janji Allah (Samuel Umbu Pingge, n.d.). Maka, dapat diambil kesimpulan bahwa praktik sunat mengandung suatu makna teologis perjanjian antara keturunan Abraham dan Allah yang membenarkan kehidupan mereka sebagai bangsa yang terpilih dan dikuduskan (dikhusukan). Sehingga praktik ini tidak semena-mena menjadi bentuk perjanjian Allah secara fisik kepada umat-Nya, namun juga mengandung makna batiniah didalamnya.

\section{Budaya Sunat di Kalangan Masyarakat Nias}

Suku Nias adalah sekelompok masyarakat yang hidup di pulau Nias. Dalam bahasa aslinya, masyarakat Nias menamakan diri mereka Ono Niha (Ono: anak/keturunan; Niha: manusia) dan pulau Nias sebagai Tanö Niha (Tanö: tanah). Suku Nias adalah masyarakat yang hidup dalam lingkungan adat dan kebudayaan yang masih tinggi. Masyarakat Nias 
kuno hidup dalam budaya megalitik (batu besar) yang dibuktikan dengan peninggalan sejarah berupa ukiran pada batu-batu besar yang masih ditemukan di wilayah pedalaman khususnya di Teluk Dalam (Nias Selatan), Onolimbu (Nias Barat) dan di tempat-tempat lain sampai sekarang.

Suku Nias adalah suku yang sampai hari ini masih memegang teguh dan menjalankan tradisi budayanya. Sebelum Kekristenan masuk ke pulau Nias, ono niha memiliki pandangan bahwa "diri" adalah ciptaan para ilah. Ono Niha menganggap diri sebagai babi ilah atau peliharaan ilah. Dikatakan babi karena peliharaan di Nias adalah babi. Ono Niha dianggap sebagai bagian dari kebudayaan. J.W.M. Bakker mengatakan bahwa "ketika manusia menjadi bagian dari budaya itu sendiri, maka manusia tidak bisa menanggalkan dalam dirinya kebudayaan" (J.W.M Bakker 1984). Begitu juga dengan masyarakat di Pulau Nias, sunat sudah menjadi salah satu kegiatan yang membudaya di masyarakat Nias, seseorang dari umur 6 tahun memenuhi hukum adat dan budaya pertamakalinya dengan melakukan sunat.

Secara terminologis sunat adalah membuka atau memotong kulit khatan (kulup) yang menutupi unjung kemaluan dengan tujuan agar bersih dari najis. Dalam pelaksanaan khitan biasanya digunakan untuk laki-laki atau istilah dalam bahasa Jawa biasanya disebut sunatan. Dalam ilmu kedokteran disebut circumcison (sunat) artinya memotong bagian kulit 
yang menutupi kepala penis (praeputium glandis). Sunat adalah pemotongan sebagian dari organ kelamin laki-laki dan pelaksanaan sunat, di setiap tempat, dilakukan dengan memotong kulup penis laki-laki. Sunat atau sering disebut dikalangan masyarakat sebagai pemotongan kulup dipandang dari dua perspektif, budaya dan agama. Tradisi sunat sampai saat ini masih berlangsung dalam kebudayaan. Sunat di setiap daerah sering dipandang sebagai peristiwa sakral, sama seperti upacara perkawinan. Hal ini tidak terlepas dari asal usulnya yang ternyata mengindikasikan nilai budaya terlebih dahulu.

Berbicara tentang budaya atau kebudayaan, secara umum kata kebudayaan berasal dari Bahasa Sansekerta, yaitu buddayah, yaitu bentuk jamak dari buddhi (budi atau akal). Dengan demikian, kebudayaan berarti hal-hal yang bersangkutan dengan akal. Kata buddayah sebagai seuatu perkembangan dari majemuk budi-daya yang berarti 'daya dari budi'. Oleh karena itu mereka membedakan budaya dari kebudayaan, budaya adalah daya dari budi yang berupa cipta, karsa dan rasa sedangkan kebudayaan adalah hasi dari cipta, karsa dan rasa itu. Kroeber dan Kluckhohn mengatakan bahwa "kebudayaan adalah manifestasi atau penjelamaan kerja jiwa manusia dalama arti seluas-luasnya."(Noorkasiani dan Heryati 2007, 12-13) Dengan demikian makna dari kata budaya adalah sesuatu yang berbeda di luar kemampuan individu, di luar kemampuan perseorangan, dan memaksakan kehendaknya pada setiap 
individu. Artinya budaya merupakan tekanan sosial masyarakat yang di dalamnya terdapat bagian-bagian seperti pola berpikir dan tindakan dan juga harus diturunkan kepada generasi berikutnya.

Berbicara tentang budaya, Nias adalah salah satu daerah yang masih memelihara budanyanya dengan sangat kuat. Hal ini dapat dilihat dari kebiasaan-kebiasaan yang diturunkan secara turun temurun kepada anak-anak mereka. Alasannya adalah untuk mempertahankan lakhomi (wibawa, penghargaan, harga diri, atau martabat). Lakhomi dianggap sebagai bukti seluruh identitas Ono Niha.(Postinus Gulo 2015)

\section{Sunat Budaya Nias}

Suku Nias, yang mayoritas beragama Kristen Prostestan, pada umumnya memraktikan sunat sebagai adat budaya asli yang sampai sekarang masih dipertahankan. Sunat dilakukan bagi anak lelaki, dengan standar umurnya sudah genap 6 tahun. Setiap anak laki-laki Nias jika sudah berumur 6 tahun dipandang sudah mencukupi umur untuk disunat menurut adat dan budaya Nias. Dalam masyarakat Nias, setiap orang yang belum disunat dikenakan hukum famago bawa (penutup mulut), maksudnya orang tersebut dianggap tidak berhak berpendapat atau berbicara atau berbicara dalam pertemuan formal, karena belum melaksanakan adat istiadat (yaitu: disunat). Sunat diberlakukan bagi anak laki-laki berusia 6-16 tahun. Hal ini berdampak bagi stigma yang dikenakan kepada seorang laki-laki yang umurnya melebihi 16 tahun, 
namun belum disunat. la akan dianggap sebagai banci. Sunat di Nias disebut laboto (dipecahkan), karena secara teknis dilakukan pembelahan kulit (dibelah, bukan di potong) luar organ kelamin. Untuk melakukan sunat sendiri, proses sunat dilakukan oleh seorang yang bernama Ere, yang oleh masyarakat Nias dikenal sebagai dukun sunat.

Pada proses pelaksanaan dari awal hingga akhir, sehari sebelum disunat keluarga menyembelih babi muda untuk melaksanakan acara bersama seluruh warga kampung. Biasanya hati babi diberikan sebagai persembahan yang disajikan kepada Adu Zatua (dewa), tetapi karena kekristenan masuk, maka hal itu tidak diberlakukan lagi karena hati tersebut dimakan oleh warga kampung. Kemudian pembagian selanjutnya adalah rahang babi. Rahang babi (simbi mbawi) dibagikan kepada Ere, kepala kampung sebagai bentuk penghargaan, dan kepada ketua adat serta orang-orang yang dianggap pemimpin. Hal itu juga tidak luput diberikan sebagai perembahan kepada Ere. Sebelum disunat, pada dini hari sebelum anak lelaki disunat, dia harus menyiram penisnya dengan air dingin sekaligus membersihkannya. Hal ini untuk mengurangi nyeri dan perdarahan. Setelah disunat, luka diobati dengan obat manjur masyarakat Nias yaitu akho atau arang yang dihaluskan hingga sembuh.

Sejarah budaya sunat di pulau Nias diyakini berasal dari tatanan kehidupan yang diberikan ilah kepada orang Nias. Namun menurut tokoh adat, budaya dan agama yang ada di salah satu desa di pulau Nias, yaitu 
bapak Asazaro Ndruru (sebagai Badan Pengerja Majelis Jemaat di Gereja BNKP Marao), sunat di Nias berawal dari masuknya ke Kekristenan di pulau Nias, dan hal itu dilaksakan setelah sebagian orang Nias sudah menjadi Kristen dan mengikuti ajaran Protestan yang dibawa oleh para hamba Tuhan yang melakukan penginjilan dari Jerman, salah satunya adalah Tuan Deninger. Proses sunat di Pulau Nias dilakukan dengan cara: sebelum sunat dilakukan seorang anak laki-laki akan diajari oleh Ere (yang dahulu dikenal dengan istilah 'dukun' tetapi sekarang disebut dengan pemuka gereja atau Satua Niha Keriso) tentang sunat sebagai tanda penyerahan diri kepada Allah, dan yang menjadi dasar pengajaran ini adalah perjanjian antara Tuhan dengan Abraham. Kemudian dari sisi budaya, beliau menjelaskan bahwa sunat merupakan langkah awal bagi seorang anak remaja untuk memenuhi adat dan dia akan dianggap dewasa.

\section{KESIMPULAN}

Sejarah praktik sunat memang bukanlah suatu praktik yang tulen berasal dari Abraham, praktik tersebut telah Abraham adopsi dari bangsa di sekitarnya. Meskipun demikian, Abraham menggunakan praktik sunat tersebut sebagai bukti perjanjian diantara Allah dan keturunannya. Mungkin bagi beberapa orang praktik sunat tersebut hanya untuk kepentingan kesehatan, namun ada sesuatu yang bermakna di dalam praktik sunat tersebut. Sunat secara fisik merubah bentuk alat kelamin 
pria, yang menjadi suatu tanda bagi mereka bahwa keturunan Abraham mengikat perjanjian kepada Allah serta sebagai tanda etnis bangsa Yahudi. Sedangkan pelaksanaan praktik itu sendiri, ketika dilakukan mengandung berbagai makna teologis seperti yang telah diterangkan oleh Michael Fox dan Samuel Umbu Pingge.

Sama halnya dengan budaya Sunat di Pulau Nias, sisi utama yang ditekankan adalah sunat menjadi sebuah tanda penyerahan diri orang Nias kepada Allah. Di sisi lain juga, ada sebuah tatanan kehidupan baru, di mana orang yang melakukan sunat sudah melakukan langkah awal dari budaya yang berlaku dan dianggap dewasa. Terlepas dari semua itu, yang menjadi hubungan antara sunat Perjanjian Lama dengan budaya sunat di Nias adalah adanya sebuah ikatan perjanjian kepada Tuhan dan orang Nias melakukannya dengan memaknai sunat itu sendiri sebagai tanda penyerahan diri kepada Allah.

\section{DAFTAR PUSTAKA}

Caleb Strom. 2018. "The Cutting Truth about Circumcision: It Was All About Rites and Religion." Ancient Origins. 2018.

Crampton, W. Gary. 2000. Verbum Dei (Alkitab: Firman Allah). Edited by Trivina Ambarsari and Sutjipto Subeno. Cetakan Ke. Surabaya: Momentum.

D. Doyle. 2005. "Ritual Male Circumcision: A Brief History." The Journal of the Royal College of Physicians of Edinburgh 35, no. 3.

"Darah Masih Keluar Dari Bekas Luka Sunat - Tanya Alodokter." n.d. Accessed November 2021. https://www.alodokter.com/komunitas/topic/keluar-darah-dari-lukabekas-sunat-setelah-dibuka-kain-kasa-pembungkusnya. 
Derek Kidner. 1996. Yeremia (The Massage of Jeremiah). Jakarta: Yayasan Komunikasi Bina Kasih/OMF.

Derouchie, Jason. 2004. "Circumcision in the Hebrew Bible and Targums: Theology, Rhetoric, and the Handling of Metaphor." Bulletin for Biblical Research 14, no. 2.

Dewantara Bangun. 2018. "Tradisi Khitanan (Rekontruksi Pengetahuan Dari Praktik Khitan Pada Pria Non Muslim Di Kota Medan)." Universitas Sumatera Utara Fakultas IImu Sosial Dan IImu Politik.

Dunsmuir, W.D., and E.M. Gordon. 2002. "The History of Circumcision." BJU International 83, no. S1.

End, Ch Van den. 2000. Enam Belas Dokumen Dasar Calvinisme. Jakarta: BPK Gunung Mulia.

"Genesis $17:$ 10-14." n.d., 1-10.

J.W.M Bakker. 1984. Filsafat Kebudayaan Sebuah Pengantar. Jakarta: BPK \& Kanisius.

"Jangan Takut, Sunat Beri Banyak Manfaat Bagi Kesehatan." n.d. Accessed November 12, 2021. https://health.detik.com/ulasan-khas/d2284462/jangan-takut-sunat-beri-banyak-manfaat-bagi-kesehatan.

Marpay, Brian, and Simon Alexander Tarigan. 2011. "Studi Alkitab Terhadap Sunat Dalam Roma 2:25-29; 3:1 Dan Implikasinya Bagi Kehidupan Kristen Masa Kini." Jurnal Jaffray 9, no. $1 .$. https://doi.org/10.25278/jj71.v9i1.90.

Muhammad Sholeh. 2021. "Riwayat Sunat: Tradisi Bangsa Mesir, Israel Hingga Australia." Fakultasnews.Co. 2021.

Noorkasiani dan Heryati. 2007. Sosiologi Keperawatan. Jakarta: Buku Kedoteran EGC.

Panjaitan, Firman. 2019. "Memaknai Penyelamatan Zipora Terhadap Rencana Pembunuhan Musa Oleh Tuhan." Bia': Jurnal Teologi Dan Pendidikan Kristen Kontekstual 2, no. 2: https://doi.org/10.34307/b.v2i2.71.

Postinus Gulo. 2015. Bowo Dalam Perkawinan Adat Ori Moro'o Nias Barat. Bandung: Umpar Press.

Risa Herdahita Putri. 2019. "Asal Usul Sunat." Historia. 2019.

Samuel Umbu Pingge. n.d. "Baptisan Anak Orang Percaya Adalah Tanggung Jawab Yang Tidak Dapat Diabaikan." Jakarta: Sekolah Tinggi Teologi Injili Arastamar (SETIA). 
Schultz, Samuel J. 2006. Pengantar Perjanjian Lama (Taurat Dan Sejarah). Malang: Gandung Mas.

"Setelah Anak Disunat, Cek Berbagai Kondisi Yang Menyertainya - Health Liputan6.Com." n.d. Accessed November 12, 2021. https://www.liputan6.com/health/read/4000079/setelah-anak-disunatcek-berbagai-kondisi-yang-menyertainya.

Suroso. n.d. "Sunat Sebagai Tanda Perjanjian."

Walter Lempp. 1994. Kitab Kejadian 12:4-25:18. Jakarta: PT BPK Gunung Mulia.

Wismoyoadi, Wahono. 1978. Sunat Dalam Alkitab. Yogyakarta: Buletin LPK No $97 \mathrm{GKI}$ dan GKJ Jawa Tengah. 